The following is the report of Major Browne, R.A.M.C. kindly made for me on one occasion:

MAY 8TH, 1914.

\begin{tabular}{l|c|c}
\hline \multicolumn{1}{c|}{ Specimen. } & $\begin{array}{c}\text { Colonies per c.cm. } \\
\text { on Agar after } \\
48 \text { Hours at } 37^{\circ} \mathrm{C} .\end{array}$ & $\begin{array}{c}\text { Colonies perc.cm.on } \\
\text { Drigalski.Conradi } \\
\text { after 48 Hours at } \\
37^{\circ} \mathrm{C} .\end{array}$ \\
\hline $\begin{array}{l}\text { 1. Ahmednagar tap water } \\
\text { 2. Tap water alum + chlorine }\end{array}$ & $\begin{array}{l}\text { Profuse } \\
\text { Scanty }\end{array}$ & $\begin{array}{l}\text { Profuse } \\
\text { Sterile }\end{array}$ \\
3. Soda water made from (2) ... & Scanty & Sterile
\end{tabular}

This shows how reliable the method is, and it is perfectly simply carried out. In this case the whole process was left to a sepoy trained to carry it out.

\section{Cost of Process.}

To be generally used the method must not only be reliable, but also cheap. This requirement is fulfilled by my method.

To supply a battalion of 1,000 men with one gallon a head a day for a month of thirty days will require 900 (say 1,000) 5-grain tablets of potassium chlorate and 5 pounds of concentrated hydrochloric acid. 'The tablets can be purchased at Rs.1.8 (2s.) a 1,000 and acid at 8 annas (8d.) a pound. The total cost per month, therefore, for 1,000 men at a gallon a head is only Rs.4 (5s. 4d.).

The cost of boiling water is infinitely more. Soldiers are allowed four-tifths of a pound of wood a head a day for boiling drinking water. For 1,000 men this comes to $800 \mathrm{lb}$. (equals 10 maunds) a day, or 300 maunds a month. The cost of wood is 10 annas (10d.) a maund, so that the cost of boiling water comes to Rs.187.8 (£12 10s.) as against Rs.4 (5s. 4d.) for chlorine. Comment is unnecessary.

\section{Conclusions.}

Much more could be written regarding the process, its efficiency, and the ease with which it can be carried out. And there are many side questions I have not touched on. But I think I have produced sufficient evidence to warrant the method receiving a fair trial. And $I$ am sanguine enough to believe that it will not be found wanting. I advance it as a substitute for boiling of water, being quicker, more easily carried out, and as reliable. The apparatus is small, and its adoption, especially for use by troops, should diminish the long-standing difficulty of getting safe water for men to drink without keeping them waiting unnecessarily long for it.

\section{Note.}

Since writing this article I have had the method in constant use by my own regiment on service for over four months. 'The use by my own regiment on service for over four months. The waters used have been very bad in every way. Storage difficulties have been very great, yet out of a strength of 800 men
and followers I have during this period only had to send eight and followers I have during this period only had to send eight
men to hospital with intestinal complaints, only one of whom men to hospital with intestinal complaints, only one of whom
has had to be invalided to India. I have no figures regardins other regiments of our force, but understand they are not so good as mine. The method, with improvised outfits, is now being extended by use by all other units.

A MONG the French medical periodicals which have come to life asain after temporary suspension mention should have been made of the Archives des Maladies du Coeur, dcs Vaisseaux et au Sang, published under the direction of Dr. H. Vaquez, professeur aqrége at the Paris Medical Faculty, and physician to the Saint-Antoine Hospital. This valuable jourual began to appear again in January, and we regret the oversight which led to its omission from the list of resuscitated periodicals.

DR. Flaissiéres, Scnator for the Bouches-du-Rhône, although he is 64 years of arse, is on active service with the French army as méclecin-major of the first class. He has recently been mentioned in the Order of the day by the general commanding the 96 th Division for having continued to give his professional services to the wounded in his regiment on the occasion of the bombardment of a village. Dr. Flaissières, though himself suffering from illness, superintended their transfer to the ambulance, and did not leave his station till every man had been dressed and he had made his report.
A Cliniral a ferture

\section{BIRTH PALSY:}

haRRY PLATT, M.S.Lond, F.R.C.S.Eng.,

HONORARY SURGEON AND SURGEON IN CBARGE OF THE ORTHOPAEDIO DEPARTMENT ANCOATS HOSPITAL, MANCHESTER.

Birth palsy or obstetrical palsy is by no means a rare condition. It has been said to occur once in every two thousand births (Frauenthal ${ }^{1}$ ), an estimate of frequency which is in all probability rather too low. It will be the fate of a goodly proportion of practitioners to encountel this condition at least once during their professional careers. From the point of view of the general practitioner birth palsy is of special importance, as in the majority of instances the parents of the child are prone to bestow undeserved blame on the doctor who conducted the labour.

For some time it has been held by most authorities that the lesion present in birth palsy is an injury to the brachial plexus in the neck; this occurs during delivery as a result of traction applied to the head with the shoulder fixed, or vice versa. The German school of orthopaedic surgeons, most notably Lange ${ }^{2}$ and Vulpius, ${ }^{3}$ consider that a primary shoulder-joint or bone lesion is present, paralysis being either absent or of secondary importance. This view was originally propounded by Küster in 1889, who described the condition as a rotatory displacement of the upper humeral epiphysis.

Last year Turner Thomas, ${ }^{4}$ of Philadelphia, brought forward new evidence in favour of the shoulder-joint lesion theory.

Certain etiological factors are well established and accepted by all. "In the vast majority of cases birth palsy is seen in an infant born after a prolonged and difficult labour in which there was a disproportion between the size of the child and the maternal pelvis.

Statistics available show that the injury occurs more frequently in vertex than in breech presentations, but the exact relative proportions remain to be settled in the future from a large series of cases.

There are, then, two opposing theories to explain the etiology of birth palsy:

1. Primary paralysis, due to stretching or tearing of the brachial plexus.

2. Primary joint or bone lesion, with or without secondary paralytic phenomena.

Symptoms and Sigis.

Following a difficult labour in which instruments may or may not have been employed, it is noticed that one arns of the infant hangs limp and motionless. The position of the affected limb is characteristic, the arm hanging close by the side in full internal rotation at the shoulder, with the elbow extended, the forearm pronated, the fingers flexed, and in some cases obvious wrist-drop. For a few days the neck and shoulder may be tender, the infant resisting all efforts of examination and manipulation of the limb; usually no actual bruising or other superficial local signs of trauma are seen. If untreated, the subsequent progress of the case may be along one of three lines :

1. Rapid and complete spontaneous recovery may ensue, leaving the limb in a practically normal state.

2. There may be complete absence of recovery with persistence of a flail limb. This is a rare sequel.

3. Considerable recovery may take place, but in an incomplete manner, leaving a residual paralysis.

This latter event is the one usually seen, so that aftcr some weeks the arm is no longer limp but is used by the child with fair power. As time goes on in all moderate and severe cases there is an evident lack of growth in tho whole limb and shoulder girdle.

Invariably in this type of case with incomplete recovery,

* The substance of a post-graduate lecture delivered at the Ancosts Hospital, January 26 th, 1915. 
it will be foumr that in addition to a residuai paralysis wlich in actual fact may be little marked, there has developed a mechavieal obstacle to the full functional us of the arm. 'The shoulder is now fixed in the position of internal rotation: this is the result of a shortening of the subscapularis tcnelon and the adjacent joint capsule. Moreorer there may be some flexion contraction at the elbow or pronation contracture of the forearm. As the cliild grows the contractures increase and the disability is still more evident. Usually in such cases there appear's little wasting of the musculature. At this stage careful examination of the shoulder region may demonstrate Fig. 1.-Boy, aged 10. a slight prominence of the head
Posterior subluxation of of the humerus belor the acro. rosterior subluxation of of the humerus below the acro-
right shoulder-joint fol- mion, that is to say, the humerus
lowing birth palss. Note mions the prominence of the is no longer in concentric appohead of the bumcrus, the sition with the glenoid and there tion of the upyer arm, is a commencing posterior sub and the dininisled deve- luxation of the joint.

It is of the utmost importance to examine for this latter complication in all cases of obstetrical palsy. In a young plump infant it is not easy to make out a subluxation in the early stage ; in an older child the projection of the displaced head is obvious to the cye (see Fig. 1.)

The association of posterior subluxation of the shoulderjoint with obstetrical palsy was furst accurately described by Whitman in 1905.5 Fairbank $^{6}$ has recently given a very able exposition of this subject based on the experience of a unique series of cases. It is quite an estab. lished fact that subluxation is associated with the majority of cases of moderate severity. which undergo almost complete recorcry. In Fairbank's series of 37 cases, 28 showed a subluxation. Turner Thomas had 9 subluxations out of a total of 12 cases.

Out of 5 consecutive cases which have been under my care during the last six months, I found 4 with subluxation. The one uncomplicated case was under treatment for a short time, and then, owing to parental apathy, was kept away from hospital for three months and the splint discarded; on being examined quite recently after this period of neglect, it was quite certain that a posterior subluxation was now present-a striking illustration of the mode of development of this sequela.

The diagnostic features of a subluxation are as follows :

(a) The attitude of the arm. This differs from the one characteristic of the early stages of simple palsy. The a'm is now abducted a little at the shoulder, the elbow flexed, the forearm pronated and lying across the abdomen -the "stomach-aclie" attitude.

(b) 'The head of the humerus is prominent under the acromion, and there is a corresponcling lyollow in front. In a normal infant's shoulder there is a slight but distinct depression behind, just beneath the acromion; by noting the difference when the fingers are placed simultaneously below the acromion a definite bulging of the head can be appreciated in the earliest stage of subluxation. In a long-standing case the projection is evident on siglit.

(c) 'There is limitation of the movements of abduction and external rotation at the shoulder-joint, both active and passive, the scaprala moving with the humerus. 'The joint is thus fixed by periarticular contractions in a position of adduction and internal rotation.

(d) The $x$-ray appearances are quite typica!, showing an underdeveloped humerus and scapula, a small npper humeral epiphysis witha downward displacement of the liead in relation to the glenoid. In an ordinary radiogram the exact position of the head in the antero-posterior plane is not shown; stereoscopic views will demonstrate the posterior displacement.

A subluxation of the shonlder-joint may be reducible at first by simple manipulation, but the condition usually becomes fixed very rapidly. The disability resulting is considerable, and is not only manifest in the shoulder region, but is seen in the dininished utility of tho hand and forearm.

\section{Pathology.}

I. Braclial Plexus Theory.

The conception of birth palsy as a primary lesion of the bracliial plexus is one based on sound clinical, patho. logical, experimental, and operative evidence. It is generally held that the exact lesion is either a simple tearing of the nerve sheaths or a stretching, laceration. or complete rupture of the nerve trunks. Every degree of injury is possible, and may involve the whole plexus or be localized to one or more trunks.

The different clinical types-the Erb paralysis, the rare lower arm paralysis, or the complete plexus paralysisare explained by the extent and localization of the injury.

The characteristic posture of the arm is indicative of a paralysis of the deltoid, spinati, biceps, brachialis anticus, supinator longus and brevis, a muscle group supplied by the fiftil cervical segment or the anterior primary division of the fifth cervical nerve. Operations on the plexus have usually revealed the site of the lesion as the fifth cervical nerve or the junction of the fifth and sixth cervical nerves just proximal to the origin of the suprascapular nerve. Few cases have been examined post mortem, but in one described fully by Boyer $^{7}$ the actual neive roots had been tor'n close to their origin from the cord, the plexus itself being uninjured.

Clarke, Taylor, and Prout, ${ }^{8}$ in a series of experiments on the cadaver, have shown that traction on the head with a fixed shoulder, renders taut the brachial plexus cords in the neck. Increased force causes fraying or rupture of the cords, the uppermost one, the fifth cervical, being the first to give way. By further increasing the violence all grades of injury could be produced. Difficult labour obviously provides the recessary conditions for the occurrence of such an injury to the infant.

The explanation of the associated joint subluxation is quite logical. The prime factor is the early contraction of the subscapularis tendon and the adjacent joint capsule which is seen after an incomplete recovery of the paralysis. The deltoid and external rotator muscles recove: late or recover imperfectly and the joint loses important support behind, thus allowing the head of the humerus to slip backwards. Fairbank believes that in addition the pectoralis major now acts on the humerus at the insertion of the subscapularis, which is a fixed point; the humerus is adducted and flexed and cluring this movement the head is tilted backwards. Without the contracture of the internal rotators, however, there can be no subluxation.

It is instructive to compare and contrast the upper arm type of infantile paralysis with obstetrical palsy. The characteristics of the former are extreme nuscular atrophy, a flail shouldier-joint, but no fixed contracture or subluxation in the antero-posterior plane. In birth palsies there is usually little atrophy and flaccidity, but a fixed contracture and posterior subluxation of the joint are present. Brachial plexus injuries in the adult, on the other hand, generally show considerable muscle atropliy, and subluxations of the shoulder are rare.

As an uncomplicated paralytic lesion, obstetrical palsy thus presents ccrtain unexpected features, and these liave been used as evidence agaiust the primary paralysis theory.

II. Epiphyseal or Joint Lesion Theory.

In a recent contribution Vulpius ${ }^{3}$ reiterates his view that the essential lesion in birth palsy is bony. Paralysis he dismisses lightly as a secondary unimportant feature. The traction injury at birth produces a fractuie or displacement of the upper epiphysis of the humerus, which is followed later by union in the dislocated posi. tion. Lange considers thut the chicf lesion is a laceration of the anterior part of the joint capsule, the healing of which produces a tivist of the humerus at the shoulderjoint in the position of internal rotation, but with no dislocation.

Turner Thomas has enthusiastically supported the shoulder-joint theory, and has brought forward a new conception of the mode of production of the injury. Thomas believes that in all cases the joint capsule is damaged, and in addition, in the majority of instances, an actual subluxation is produced at the time of birth; this subluxation is difficult to diagnose, and therefore is invariably missed in the first few weeks. The resulting 
scar tissue from the lacerated capsule involves the brachial plexus cords lying in close proximity to the shoulder-joint, causing paralytic phenomena which are usually slight and transient.

Whe violence producing this shoulder-joint injury is not traction during delivery, but pressure, exerted by the bony pelvic wall on the anterior aspect of the infant's shoulder whilst still in utero. According as to the degree of back. ward pressure there is either a toaring o? the joint capsule or a subluxation of the joint.

In Thomas's seli is of 12 cases 11 sl.owed an affection of the right side, and as the right shoulder is anterior in the majority of labours this (according to the author) explains the preponderance of right-sided cases. Furthermore, in all cases the acromion process showed the effect of the pelvic compression, the anterior part of the tip being bent downwards, thus forming an obstacle to the complete reduction of the subluxation. This acrumial deformity is a new physical sign described only by 'Thomas.

In further support of his theory, Turner Thomas has adduced arguments against the conceptions of Whitman and Fairbank. It is said that the plexus theory does not cxplain the rapid recovery of the paralysis, the unsatis factory results of electrical tests, the absence of sensory symptoms, the evidence of operative prosedures in which scar tissue has been found merely around the nerve trunks, and the occurrence of rupture of the nerve roots at their origin from the cord, as in Boyers's case. These objections really have little weight and can be readily met. Rapid recovery is not incompatible with slight injuries localized to the nerve sheaths only; learing scar tissue surrounding, but not invading, the intact cords. Electrical reactions are unsatisfactory in all forms of paralysis unless the electrodes are directly inserted into the affected muscles; in infants the results are specially inaccurate. Sensory symptoms could hardly be appreciated accurately in infants, and as the typical lesion is one corresponding to the distribution of the fifth cervical anterior primary division, sensory disturbances would not be appreciable. Finally, the known occurrence of rupture of the nerve roots high up does not preclude the possibility of rupture at a lower level.

The hypothesis bronght forward by Thomas can be fairly criticized on several grounds. In the first place 12 cases is too small a number from which to draw dog matic conclusions. In Fairbank's 28 cases the two arms vere affected in equai numbers. To establish a relation. ship betiveen the shoulder involved and its position in uter. demands an accurate knowledge of the presentation in every case. It is true that the right shoulder lies anterior in the majority of normal fetal positions, but obstetrical palsy is almost invariably seen after an abnormal labour, in which it is more than probable that an unusual presentation was encountered.

Personally I have been unable to discover the acromial deformity on which 'Thomas lays so much stress in 5 cases which I examined specially for this point. There is no reason to doubt that on the affected side the acromion shares in the lack of development which is evident also in the glenoid and coracoid; this is a secondary change due to the presence of a persistent unreduced subluxation of the joint, and is manifested as a diminution in size and a change in contour of the process.

It cannot be denied that shoulder-joint subluxation dominates the clinical picture of birth palsy. Turner Thomas states that in neglected cases the unreducd dislocation explains the limitation of movement and loss of power in the limb. Fairbank, on the other liand, found that in 10 out of 28 cases there was a residual paralysis of the extensors of the wrist and fingers.

Although there is at present scanty evidence to support the theory expounded by Turner Thomas, there is a certain armount of evidence in favour of a primary epiphyseal or joint lesion in some cases of obstetrical palsy. It is probable that the combination of physical signs presented in birth palsy may be produced by a pure plexus lesion, a joint lesion, or an epiphyseal displace. ment. The differential diagnosis of the three conditions in a very young infant is well-nigh impossible. As the treatment is the same for all the diagnostic disability is happily not of great practical importance. Both Biesalski ${ }^{9}$ and Rosenfeld ${ }^{10}$ recognize two types-the primary nerve lesion and the joint lesion-but admit the difficulty of distinguishing between the two. It is a reasonable conception to hold at the present time that obstetrical palsy is in the majority of cases a primary plexus injury, but in a certain unknown proportion of cases is a shoulder-joint or epiphyseal lesion.

It is noteworthy that the theory which explains the violence as pelvic compression entirely eliminates the participation of the accoucheur, and therefore, if supported, might be of extreme medico-legal importance.

Treatment.

It is convenient to divide the treatment of obstetrical palsy and its associated deformities into three stages as it is usually seen by the surgeon.

\section{Simple Paralysis.}

This is the earliest stage, in the first few days or weeks after birth; the arm is limp and useless, and no contractures are present.

The arm must be fixed without delay in the position of relaxation of the paralysed muscles-that is, abducted to $90^{\circ}$, and rotated out fully at the shoulder, flexed to a right angle at the elbow, with the forearm fully supinated and the wrist and fingers hyperextended. Whilst a splint is being made this posture can be roughly maintained in a newborn infant by pinning the sleeve of the vest behind the neck. As a temporary measure in an older child a plaster-of-Paris shell can be used; such an apparatus is used permanently. at this stage by Lange. A suitable splint can be made from block tin or aluminium, the latter being advisable except in tiny infants. The splint consists essentially of a broad body piece and a narrow arm piece suitably padded and furnislied with webining straps and buckles.

'The position of relaxation must be constantly kept up night and day. In addition, daily massage and passive motions at the shoulder to prevent contracture are begun. At the first sign of recovery, exercises to train the muscles are instituted. In a young infant quite efficient exercises can be devised with the aid of toys; an enthusiastic parent or nurse can be of great value at this time. Hos. pital patients unfortunately rarely get these advantages. Massage, to be of any avail, must be quite superficial, and carried out with the muscles kept continuously relaxed. Deep kneading applied to a muscle which for the time being is completely cut off from its nerve cells is positively harmful, and massage of any kind practised on muscles which are allowed to be stretched is valueless. These facts are little appreciated by masseuses in general, and consequently a great deal of massage for paralysis of all kincls is botli dangerous and a waste of time.

The most essential part of the treatment in the early stages is the maintenance of the arm in the splint in the correct posture.

Recovery is generally rapid in the hand and forearm, the shoulder muscles lagging behind somervhat. Until there is recovery of the power of active external rotation and abduction at the shoulder there is a danger of subluxation developing, therefore the splint must be used until such recovery is established. If, in spite of efficient treatment, there is no recovery at all after three months' time, it is usually recommended that the electrical reactions of the paralysed group be tested. The presence of the reaction of degeneration after such a period has been regarded as an indication for direct operative attack on the plexus. There are obvious technical drawbacks to the testing of electrical reactions in infants, and the mere presence of the R.D. does not indicate that a muscle is past recovery. Personally, I attach little prognostic value to the electrical reactions of paralysed muscles.

The results of operations on the plexus in infants have been uniformly poor. A mass of scar tissue is encountered surrounding the small nerve cords, which are not always easy of accurate identification.

In cases of complete rupture an exact topographical end. to-end suture is impossible, and the removal of scar tissue does not guarantee that a new scar will not follow the operative manipulations. Secondary nerze suture for incomplete anatomical nerre injuries must always be an operation of little use, and fraught with much harm whenever performed.

Nerve anastomosis in the plexus region is a priori likely 
to be unsatisfactory. To be accurate and therefore suc. cessful, a nerve anastomosis must always be practised at the periphery, and not close to the origin of nerres from the cord; this has been fully proved by the work of Stoffel and Spitzy. Therefore in the rare cases of birth palsy which show little or no recovery after coriest trextment prolonged over a sufficient period, the oporative methods which are used in the residual paralysis of poliomyelitis are indicated, teuclon transplantations or arthrodrsis according as to the exact requirements. Recovery is the rule in birth palsy, cren if it is long delayed, aud therefore a patient trial ninst be given to splint treatment and massage, befoic any hasty conclusion is arrived at. It is a striking fact that flail limbs followiug obstetrical lalsy are practically unknown in adults.

II. Internal Rotation Deformity at the S'houlder.

Cases neglected for several months usually present the nlove feature. The position of the head of the humerus should be carefully ascertained, and if no subluxation be present an anaesthetic inust be given and energetic stretching of the contracted capsule carried ont, especially in the direction of exterinal rotation and abduction, the scapula being firmly fixed during these manipulations. The limb is then placel in the same position as is used in the first stage, either in a splint or better in plaster for a tew weeks, and afterwards on a $T$ splint. The usual massage, manipulations, and cxercises then follow.

If the capsule camnot be stretched fully by manipulations in open operation is nccessary in which the contracted parts are divided.

In children over 2 year's of age with the internal rotation deformity, Lange, Vulpius, and other's recommend the performance of an ostcotomy of the htmerus with rotation out of the lower fragment. In the first place, this is dealing with a contracture of soft parts by a bone operation; and in the second place, it is very likely that an unrecognized sibluxation of the joint is present, the direct operative treatment of which gives better functional results than csteotomy of the humerus.

III. Posterior Subluration of the Shoulder-joint.

One may be confronted with this sequela in an infant, an olter child, or in an untreated adult. It may be possible in the carly stages of subluxation to accomplish reduction without an anaesthetic, but generally the deformity is so fixed as to demand considerable force. Whitman has successfully reduced a number of such cases by manipula tions uncler anaesthesia; in some instances to obtain full recluction repeated efforts were required. The shortening of the capsule is often so great that manual force, unless approaching a dangerous degree, is insufficient.

Fairbank has found it nccessary to perform an arthrotomy to cffect reduction in rost of his cases, even at an early agc. Over the age of two years an open operation will

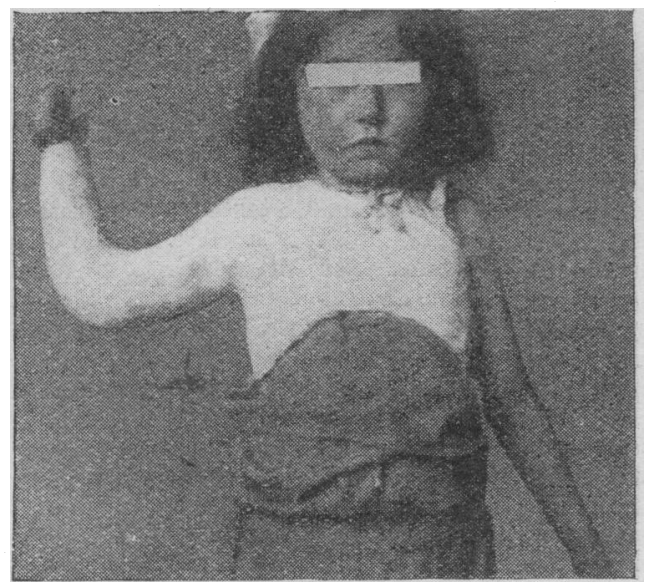

Fig. 2.-Position of limb in plaster after reduction of subluxation by an open operation.

always be indicated. The joint is best approached by the anterior route and the anterior capsule with the subsiajularis tendon insertion freely divicled. The acromion may appear as an obstacle to reduction and requirc partial r'cmoral. 'l'urner' Thomas recommends its removal as a routine. After reduc-

tion and closure of the wound, a plaster-ofParis casc is applied, fixing the limb in ful external rotation witl the elbow well back; the original position devised by Whitman was to keep the atm ad. ducted to the side, bui the functional results are better if the typical oustetrical palsy position be employed. (Fig. 2.)

After three months' fixation, massage aud movements are neces sary if full mobility is to be attained. The functional result indced depends very largely

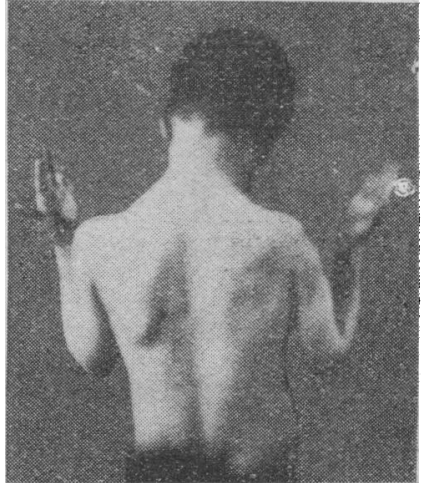

Fig. 3.-Result of open operation for reduction of subluxation. Note the and comparo with Fis. 1 . on efficient after-treatment. In a long-standing subluxation the distorted head and glcnoid are factors which modify considerably the after'results of a successful reduction. In this connexion subluxation of the shoulder resembles congenital dislocation of the hip-joint.

Franenthal, American Brblographr.

hildren Children, vol. Jxv, No. 4. 1912. ${ }^{2}$ Lange, Muench. med. Woch.. 1912, Nr. ¿6. Vulpius, Dentsch. med. Wcch May, 1917. "'Turner Thomas, Annals of Surgery, February, 1914. "Whitman, Annals of Surgery, Med. (Nemrology Sectiou, 1912 8 Clarke, Taylor, Prout, Journ. Med. Science October 1906 9 Biessiski, peidlie, Lange, 1914. 10 Rosenfeld, Lehirbuch der Orthopüitie, Lange, 1914

\section{DECORTICATION FOR TRAUMATIC EMPYEMA WITH COMPLE'IE COLLAPSE OF LUNG. \\ BY}

WALTER G. SPENCER, M.S., MAJOR R.A.M.C.(T.) SURGEON TO THE WESTMINSTER hospital.

Is the present war it seems that cases which survivc wounds of the thorax rarely develop empyema, and traumatic empyema does not now claim the attention devoted to it by the writers on military surgery in the past. The case to be described is further noteworthy in that the empyema developed without obvious signs, the wound healing by first intention; nevertheless, in the course of three weelis from the injury the lung had become so bound down by inflammatory fibrous tissue that nothing but the moäified Delorme's operation of decortication could have availed the patient.

A private, woundel on November $4 \mathrm{th}$, was admitted to the 4th London General Hospital on November 27th, 1914, where I hat the advantage of the assistance of Lieutenant Comyn as house-surgeon and Lieutenant Davis as anaesthetist. On admission, the man was found to be pale, weak, short of breath, and had lost flesh ; the temperature was $102^{\circ} \mathrm{F}$., the pulse 108, and the respirations 32 . He had been wounded by shrapuel, which had penetrated the thorax under the risht axilla at the level of the fourth rib. The external wound had practically healed, a fragment had lodged in the fourth rib, and another fragment in the lower part of the pleural cavity. There narrow zone of lullness to percusion above the level of the liver but the impaiment of percision above the level of the as the angle of the seapula as the angle of the scapula. Except for this sign, auscultation and percussion seemed normal in character. From the dull zone Lieutenant Comyn drew off pus mixed with blood.

On November 30th (twenty-six days after the injury) I removel a portion of the eighth rib, and found the whole pleural cavity filled with a loculated mass composed of blood clot, cheesy fibrin, and purulent fluid mixed with foul gas. It was only after considerable sponging and scrubbing that the fibrinous masses could be detached and removed, but when this was completed there was no sign of any expansion of the Inng, which remained in a state of complete collapse. As a result of this operation the patient's temperature fell to normal, the respirations to 26 and the puise to about 100 . Ten days later, on December 9 th, as there was still no sign of any re-expansion of the 9 , I enlarged the opening by removing portions of the seventhang, ninth ribs, so as to be able to insert a part of the seventh and lung was absolutcly bound down, being covered by a tough 